\title{
Study on the Link between Lead Exposure and Hematological, Psychological, and Memorial Parameters in Automobile Repair Workers
}

\author{
Davood Fazli1, Ali Akbar Malekirad1,2,3, Mahtab Mirzaee4, Hajar Akbari Dastjerdi1, \\ Sara Mostafalou ${ }^{2,3}$, Azam Karkhanes, Zahra Bayrami2,3, Mohammad Abdollahi2,3* \\ ${ }^{1}$ Biology Department, Payame Noor University, Tehran, Iran \\ ${ }^{2}$ Environmental Toxicology and Human Health Group, Tehran, Iran \\ ${ }^{3}$ Faculty of Pharmacy and Pharmaceutical Sciences Research Center, Tehran University of Medical Sciences, \\ Tehran, Iran \\ ${ }^{4}$ Psychology Department, Arak University, Arak, Iran \\ ${ }^{5}$ Faculty of Biochemistry, Tehran University of Medical Sciences, Tehran, Iran

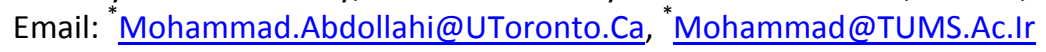

Received 7 January 2014; revised 10 February 2014; accepted 18 February 2014

Copyright (C) 2014 by authors and Scientific Research Publishing Inc.

This work is licensed under the Creative Commons Attribution International License (CC BY). http://creativecommons.org/licenses/by/4.0/

(c) (7) Open Access

\section{Abstract}

In the surrounding environment, lead $(\mathrm{Pb})$ can be released by repairing some parts of automobile engine and radiators repair works. Lead is very well-known as a neurotoxicant as some links exist between blood lead level (BLL) and neurological outcomes. This cross sectional study was performed on 35 male workers who were 23 - 40 and worked in an automobile repair shop located in an industrial part of Tehran. Clinical evidences were recorded by a questionnaire. Subjects had given their blood samples between 7 and 8 a.m. before going to work. The levels of hematological parameters were measured and the amount of lead in plasma samples was determined by graphite-furnace atomic absorption spectrophotometer. The Iranian versions of mood state and Wechsler memory questionnaire were applied in order to evaluate mood and memory impairment. The association between variables was studied using Pearson correlation coefficient. A positive correlation was seen between workers' history on one side and, urinary frequency and restlessness on the other side. There was not any meaningful relationship between worker history, blood parameters, and mood state. A negative meaningful relationship existed between the workers' history and visual memory. Also a positive significant relationship was observed between BLL and epigastric pain and there was a negative relationship between BLL and repeat number. There was not a significant relationship between BLL, blood parameters, and mood state as well. It was

\footnotetext{
${ }^{*}$ Corresponding author.
} 
concluded that work practices in the automobile repair shop seemed to increase the body burden of lead and may pose a health risk to the workers.

\title{
Keywords
}

\author{
Lead; Mood State; Memory Disorders; Automobile Repair Shop
}

\section{Introduction}

Though lead $(\mathrm{Pb})$ is recognized as an ecological hazard. It is a beneficial element in several industries and is brought in production of lead bullets and the batteries, or in refinery industries to purify gold and silver. In such factories, the workers can be exposed to the dusts or fumes of lead if protective tools are not properly used and it would end up with a serious health problem [1]-[4].

Automobile repair shop is one of the work places where workers are subjected to lead and other toxic chemicals during the process of repairing the automobiles' engine and radiator. Studies have shown that nearly $36.4 \%$ of the automobile garage workers suffer from some forms of pulmonary problems; obstructive and/or restrictive [5].

Lead is a well-known neurotoxicant as there are some links between blood lead level (BLL) and malfunction of human cognition [6] [7]. Moreover attention and intelligence rate in children can be negatively affected by lead [8] [9]. Lead has been shown to cause neurobehavioral problems [10] or neurobiological defects such as schizophrenia [11]. The association of lead contamination and incidence of Alzheimer's disease has also been verified [12]. It is anticipated that cardiovascular outcomes and mild mental retardation resulting from exposure to lead encompass almost $1 \%$ of the global burden of illness peaking in undeveloped regions [13].

The current study was planned to consider the condition of mood and memory state, hematological parameters and clinical markers in relation to BLL in the workers of automobile repair shop.

\section{Methods}

The study was performed on 35 male workers who were 23 - 40 and worked in an automobile repair shop located in an industrial part of Iran. In accordance with ethical rules of Pharmaceutical Sciences Research Center (PSRC) of Tehran University of Medical Science where the study protocol was confirmed, all participants were informed concerning the purposes of the research and achieved the printed consent. Before collecting blood samples, each individual had an extensive interview with a specific physician who filled a structured questionnaire about his possible diseases and dietary habits. Information on experience job, socioeconomic situations like income and education, and history such as drug uses, consumption of vitamins or antioxidant supplements, smoking, alcohol consumption and dietary habits were acquired from questionnaires and every worker was interviewed by an educated interviewer. A summary of demographic data on workers and control subjects is presented in Table 1. All the subjects were aware of the study protocol and their permission was taken before entering the study. The research was proved by PSRC Ethics Review Board. The amount of lead concentration in plasma samples was measured by graphite-furnace atomic absorption spectrophotometer. The Iranian versions of mood state and Wechsler memory questionnaire were applied for evaluating mood and memory impairment. All the subjects were submitted to comprehensive clinical assessment to diagnose symptoms of lifelong diseases. Those who had any history of chronic disease, alcohol drinking, use of antioxidant/vitamin supplements or other drugs, exposure to other toxic compounds, radiotherapy, and substance abuse were rejected from participating in research. The blood samples of subjects were gathered between 7 and 8 a.m. before their entrance to the workplace. The levels of mean corpuscular hemoglobin (MCH), white blood cell (WBC), neutrophil, lym-

Table 1. Brief explanation of demographic data in workers.

\begin{tabular}{ccccccc}
\hline Subjects & Age (yrs) & Sex & Work history (yrs) & Smoking (yrs) & Smoking (N/day) & BMI \\
\hline Workers $(\mathrm{n}=35)$ & $31.37 \pm 3.79$ & Male (100\%) & $10.60 \pm 5.35$ & $1.90 \pm 4.26$ & $1.8 \pm 4.17$ & $25.38 \pm 2.09$ \\
\hline
\end{tabular}

Data represent mean \pm SD. 
phocyte, mean corpuscular volume (MCV), monocyte, eosinophil, basophil, platelet crit (PCT), red blood cell (RBC), hemoglobin, hematocrit, mean corpuscular hemoglobin concentration (MCHC), red blood cell distribution width (RDW), platelet (PLT), mean platelet volume (MPV) and platelet distribution width (PDW) were measured. Further the amount of $\mathrm{Pb}$ in the plasma samples was determined by a graphite-furnace atomic absorption spectrophotometer.

\subsection{To assess Affective Mood State Fluctuation}

The Iranian version of Profile of Mood States (POMS) assessment has been proven itself to be an excellent measure of affective mood state fluctuation in a wide variety of populations including psychiatric outpatients, medical patients, and in sports psychology. The POMS assesses transient and fluctuating affective mood states. The POMS measures six identifiable mood or affective states: 1) Tension-Anxiety; 2) Vigour-Activity; 3) Depression-Dejection; 4) Fatigue-Inertia; 5) Anger-Hostility; 6) Confusion-Bewilderment [14].

\subsection{Wechsler Memory Scale}

The Iranian version Wechsler Memory Scale (fourth edition) is used for the evaluation of memory state. The Wechsler Memory Scale (WMS) is a neuropsychological test which designed to measure different memory functions in a person. The memory sub scale of WMS-IV is made up of eight subtests: Personal information, Orientation, Mental control, Logical memory, Repeat number, Visual memory, and also IQ used for assay the memory [15].

\subsection{Statistical Analysis}

Pearson correlation coefficient was applied to examine the relationship between the variables. The data are accessible as mean \pm SD. The P values less than 0.05 were considered statistically significant. Stats Direct 2.7.9 was used to analyze data.

\section{Results}

In Table 1 the median levels of participants' age, index body matrix (IBM), employment years, smoking habits (years and N/day), and sex are displayed.

Table 2 explains that there is no major association between BLL and work history on one side, and anger, depression, fatigue, friendly, tension and vigor on the other side.

As shown in Table 3, both BLL and workers history had considerable positive correlations with some clinical symptoms like urinary frequency, wrist drop, less concentration, insomnia, headache, abdominal pain, tremor, fatigue, history of family hypertension, numb ling, agitation, and hypersomnia.

Table 4 clarifies an important correlation between BLL on one side and workers history on the other side with some parameters of memory state including personal information, orientation, mental control, logical memory, repeat number, visual memory, association memory and intelligence quotient (IQ).

Table 5 shows that there is no significant relationship between hematological parameters of workers with BLLand workers history.

Table 2. The associationof psychological distresses with BLL and work history.

\begin{tabular}{ccccc} 
& \multicolumn{2}{c}{ BLL $(38 \pm 10.7 \mu \mathrm{g} / \mathrm{dl})$} & \multicolumn{2}{c}{ Workers history } \\
\cline { 2 - 4 } & $\mathrm{R}$ & $\mathrm{P}$ & $\mathrm{R}$ & $\mathrm{P}$ \\
\hline Anger & -0.097 & 0.609 & -0.123 & 0.516 \\
Depression & -0.055 & 0.773 & -0.021 & 0.914 \\
Fatigue & -0.158 & 0.404 & -0.185 & 0.328 \\
Friend & -0.185 & 0.329 & -0.033 & 0.861 \\
Confusion & -0.226 & 0.230 & -0.202 & 0.283 \\
Tension & -0.042 & 0.329 & -0.203 & 0.281 \\
Vigor & -0.091 & 0.633 & -0.001 & 0.995 \\
\hline
\end{tabular}


Table 3. The association of clinical symptoms with BLL and work history.

\begin{tabular}{ccccc}
\hline & \multicolumn{2}{c}{ BLL $(38 \pm 10.7 \mu \mathrm{g} / \mathrm{dl})$} & \multicolumn{2}{c}{ Workers history } \\
\cline { 2 - 4 } & $\mathrm{R}$ & $\mathrm{P}$ & $\mathrm{R}$ & $\mathrm{P}$ \\
\hline Urinary Frequency & -0.017 & 0.929 & 0.402 & 0.028 \\
History of family hypertension & -0.260 & 0.165 & 0.038 & 0.842 \\
Numbless & 0.160 & 0.399 & 0.068 & 0.423 \\
Wrist drop & 0.293 & 0.115 & 0.147 & 0.355 \\
Less concentration & -0.157 & 0.406 & -0.175 & 0.001 \\
Agitation & 0.189 & 0.318 & 0.595 & 0.673 \\
Fatigue & 0.001 & 0.996 & -0.080 & 0.413 \\
Tremor & 0.460 & 0.010 & 0.155 & 0.146 \\
Headache & 0.132 & 0.487 & 0.272 & 0.597 \\
Epigastric pain & 0.515 & 0.004 & -0.101 & 0.449 \\
Hypersomnia & -0.189 & 0.316 & -0.144 & 0.829 \\
Insomnia & -0.030 & 0.874 & -0.041 & \\
\hline
\end{tabular}

Table 4. The association of memory states with BLL and work history.

\begin{tabular}{ccccc}
\hline & \multicolumn{2}{c}{ BLL $(38 \pm 10.7 \mu \mathrm{g} / \mathrm{dl})$} & \multicolumn{2}{c}{ Workers history } \\
\cline { 2 - 5 } & $\mathrm{R}$ & $\mathrm{P}$ & $\mathrm{R}$ & $\mathrm{P}$ \\
\hline Personal information & -0.025 & 0.896 & 0.221 & 0.241 \\
Orientation & 0.513 & 0.004 & -0.162 & 0.392 \\
Mental control & 0.271 & 0.148 & -0.061 & 0.748 \\
Logical memory & 0.082 & 0.667 & -0.114 & 0.549 \\
Repeat number & -0.432 & 0.017 & -0.336 & 0.069 \\
Visual memory & -0.033 & 0.861 & -0.507 & 0.004 \\
Associationmemory & -0.061 & 0.751 & -0.139 & 0.463 \\
IQ & -0.047 & 0.441 & -0.235 & 0.212 \\
\hline
\end{tabular}

\section{Discussion}

According to the results of this study, BLL higher than allowed limit $(30 \mu \mathrm{g} / \mathrm{dL})$ observed in the workers verifies the presence of contamination and absorption of lead into the body. In this regard, many studies have already reported that BLL in such workers is higher than controls. Suplido and Ong (2000) indicated that the body burden of lead increased by radiator repair activities. Though it was not much higher than the level of unexposed counterparts, BLL in workers and their children was greater than before battery recycling/repair activities [16]. Further, it had been shown that children of radiator repair workers were at higher risk of lead exposure than other children [17]. Extensive lead exposure in an automotive radiator repair industry had also been reported [18]. According to WHO and CDC criteria, children living around automobile and battery repair workshops had notably higher lead and lower hemoglobin levels in blood [19].

The results of our analyses showed that there was a considerable association between BLL and some clinical signs, hematological parameters, and memory disorders in workers. Our previous study on lead-zinc mine workers indicated that they suffered from clinical symptoms like memory loss, less attention, sleeplessness, headache, claudication, epigastric pain, lack of appetite, anxiety, tremor, lessened reflect of deep tendon, deafness, and ti- 
Table 5. The association of hematological parameters with BLL and work history.

\begin{tabular}{|c|c|c|c|c|}
\hline & \multicolumn{2}{|c|}{ BLL $(38 \pm 10.7 \mu \mathrm{g} / \mathrm{dl})$} & \multicolumn{2}{|c|}{ Workers history } \\
\hline & $\mathrm{R}$ & $\mathrm{P}$ & $\mathrm{R}$ & $\mathrm{P}$ \\
\hline WBC (cells/mcL) & -0.051 & 0.778 & 0.227 & 0.204 \\
\hline Neutrophil & -0.30 & 0.09 & -0.205 & 0.251 \\
\hline Lymphocyte & 0.209 & 0.243 & 0.155 & 0.388 \\
\hline Monocyte & -0.09 & 0.617 & 0.187 & 0.296 \\
\hline Eosinophil & 0.284 & 0.11 & 0.044 & 0.808 \\
\hline Basophil & -0.220 & 0.219 & -0.298 & 0.092 \\
\hline RBC (cells/mcL) & -0.034 & 0.849 & 0.047 & 0.795 \\
\hline Hemoglobin (g/dL) & -0.086 & 0.633 & 0.093 & 0.605 \\
\hline Hematocrit (\%) & 0.023 & 0.897 & 0.206 & 0.251 \\
\hline $\operatorname{MCV}(f l)$ & 0.316 & 0.074 & 0.164 & 0.36 \\
\hline MCH (pg) & -0.104 & 0.563 & 0.166 & 0.355 \\
\hline MCHC (\%) & -0.028 & 0.877 & -0.016 & 0.928 \\
\hline RDW (\%) & -0.160 & 0.374 & -0.122 & 0.499 \\
\hline Platelets (×109/L) & 0.161 & 0.371 & 0.010 & 0.958 \\
\hline MPV & 0.016 & 0.931 & 0.098 & 0.587 \\
\hline PCT & 0.255 & 0.152 & -0.006 & 0.972 \\
\hline PDW & -0.049 & 0.785 & -0.339 & 0.054 \\
\hline
\end{tabular}

redness [20]. In fact, exposure to lead could be manifested by symptoms like anemia, abdominal colic, peripheral and central neuropathy, or could last asymptomatic limited to vague indicators such as myalgia, tiredness, bad temper, and headache [21]. A study conducted on petrol employees showed a numerical increase (vs. controls) in the incidence of tremor and sinus bradycardia [22] similar to the results of our research work.

The result of this research pointed that there would be a positive correlation between BLL and memory disorders. Canfield et al. (2004) declared that children having higher rate of lead exposure weakly reacted on tests of executive processes. In both bivariate and multivariate analyses, children with BLL upper than lifetime middling concentrations showed impaired performance on the tests of spatial working memory, spatial memory span, intradimensional and extradimensional shifts, and an analog of the Tower of London task [23]. Another study had indicated that there was a link between BLL and lesser intelligence quotient (IQ) as well, but IQ was not responsible for impact on hyperactivity [24].

Analysis applied in this study showed that there was no major association between BLL and different parameters of mood disorders. Although there were some reports on the raised frequency of symptoms like anger, depression, fatigue, and joint pain in lead exposed people [25], Lindgren et al. (1996) revealed that neuropsychological performance should be evaluated in association with cumulative exposure to lead. In their study, the current BLL was low and didn't have any relation to neuropsychological performance. But neuropsychological performance was found to be related to time integrated blood levels (IBL) developed by applying a suppressor variable, years of employment, in the model [26].

Prior study on mine workers who were co-exposed to lead and zinc indicated that the mean scores of anxiety, physical complaints and aggression scales were significantly higher in the case group in comparison to those of controls [27]. Converse relation between BLL and finger-wrist tapping-speed had been already reported by another study suggesting a fundamental relationship between mental lead exposure and certain neurobehavioral deficits [28]. It had also been proposed that behavioral impacts related to low-level lead exposure were mediated by attentive deficits [29]. 
Recently lead had been shown to have a negative result on cognitive operations in children [7] and its postnatal toxicity could be a causative factor in the pathogenesis of autism. Variation ingamma amino butyric acid (GABA), serotonin (5HT) and dopamine (DA) had been known to be responsible for chronic lead toxicity in autism [30]. Some hypotheses had been proposed on the hypo function of the N-methyl-d-aspartate (NMDA) pathway throughout serious periods of growth as a connecting dot between early life exposure to lead and neurobiological outcomes associated with schizophrenia [11]. Further, an inverse relationship between children's neurodevelopment and BLL even in the ranges less than $10 \mu \mathrm{g} / \mathrm{dL}$ had been reported in association with neurobehavioral outcomes [10].

It sounded that many other factors involved in workers' lifestyles were engaged in neurocognitive impairment, but unknown roles of the lead with a highlighted background in damaging different parts of nervous system should not be ignored, particularly in low level and long term exposures. These conclusions warned that silent toxicological problems could be induced by lead that might not be easily known by the health professionals [31] [32]. Workers' education, use of personal protective equipment's, and discontinuing the use of lead as much possible, were suggested as helpful measures in lowering the toxic effects of occupational exposure to lead. The accurate use of shielding implements and taking day-to-day bath by workers could assist to protect them and specially their children from exposure to lead and other poisonous elements. The limitations of the study were the lack of measurement of air lead and also the lack of control diet.

\section{Acknowledgements}

The researchers want to express sincere gratitude to subjects who were patient in co-operating in this research. To some extent, this study was funded by Payame Noor University (PNU). Furthermore, their appreciation goes to the assistance of Iran National Science Foundation (INSF).

\section{References}

[1] Abdollahi, M., SadeghiMojarad, A. and Jalali, N. (1996) Lead Toxicity in Employees of a Paint Factory. Medical Journal, 10, 203-206.

[2] Karrari, P., Mehrpour, O. and Abdollahi, M. (2012) A Systematic Review on Status of Lead Pollution and Toxicity in Iran; Guidance for Preventive Measures. Daru, 20, 2. http://dx.doi.org/10.1186/1560-8115-20-2

[3] Kebriaeezadeh, A., Abdollahi, M., Sharifzadeh, M. and Mostaghasi, R. (1997) Lead Levels in the Inhabitants of Tehran City Districts. Pajouhandeh, 2, 67-72.

[4] Staudinger, K.C. and Roth, V.S. (1998) Occupational Lead Poisoning. American Family Physician, 57, 719-726.

[5] Chattopadhyay, O. (2007) Pulmonary Function in Automobile Repair Workers. Indian Journal of Community Medicine, 32, 40-42. http://dx.doi.org/10.4103/0970-0218.53393

[6] Lanphear, B.P., Dietrich, K., Auinger, P. and Cox, C. (2000) Cognitive Deficits Associated with Blood Lead Concentrations $<10$ microg/dL in US Children and Adolescents. Public Health Reports, 115, 521-529. http://dx.doi.org/10.1093/phr/115.6.521

[7] Pawlas, N., Broberg, K., Olewińska, E., Prokopowicz, A., Skerfving, S. and Pawlas, K. (2012) Modification by the Genes ALAD and VDR of Lead-Induced Cognitive Effects in Children. Neurotoxicology, 33, 37-43. http://dx.doi.org/10.1016/j.neuro.2011.10.012

[8] Nicolescu, R., Petcu, C., Cordeanu, A., Fabritius, K., Schlumpf, M. and Krebs, R. (2010) Environmental Exposure to Lead, but Not Other Neurotoxic Metals, Relates to Core Elements of ADHD in Romanian Children: Performance and Questionnaire Data. Environmental Research, 110, 476-483. http://dx.doi.org/10.1016/j.envres.2010.04.002

[9] Brockel, B.J. and Cory-Slechta, D.A. (1999) The Effects of Post Weaning Low-Level Pb Exposure on Sustained Attention: A Study of Target Densities, Stimulus Presentation Rate, and Stimulus Predictability. Neurotoxicology, 20, 921-933.

[10] Téllez-Rojo, M.M., Bellinger, D.C., Arroyo-Quiroz, C., Lamadrid-Figueroa, H., Mercado-García, A. and Schnaas-Arrieta, L. (2006) Longitudinal Associations between Blood Lead Concentrations Lower than 10 microg/dL and Neurobehavioral Development in Environmentally Exposed Children in Mexico City. Pediatrics, 118, e323-e330. http://dx.doi.org/10.1542/peds.2005-3123

[11] Guilarte, T.R., Opler, M. and Pletnikov, M. (2012) Is Lead Exposure in Early Life an Environmental Risk Factor for Schizophrenia? Neurobiological Connections and Testable Hypotheses. Neurotoxicology, 33, 560-574. http://dx.doi.org/10.1016/j.neuro.2011.11.008 
[12] Basha, R. and Reddy, G.R. (2010) Developmental Exposure to Lead and Late Life Abnormalities of Nervous System. Indian Journal of Experimental Biology, 48, 636-641.

[13] Fewtrell, L.J., Prüss-Ustün, A., Landrigan, P. and Ayuso-Mateos, J.L. (2004) Estimating the Global Burden of Disease of Mild Mental Retardation and Cardiovascular Diseases from Environmental Lead Exposure. Environmental Research, 94, 120-133. http://dx.doi.org/10.1016/S0013-9351(03)00132-4

[14] VaezMosavi, S.M.K. and Samandar, Gh. (2002) Standardization of Profile of Mood States in Elite Sports. Olympic Journal, 4, 5-18

[15] Orangi, M., Atefvahid, M. and Ashayeri, H. (2002) Standardization of the Revised Wechsler Memory Scale in Shiraz. IJPCP, 7, 56-66.

[16] Suplido, M.L. and Ong, C.N. (2000) Lead exposure among small-scale battery recyclers, automobile radiator mechanics, and their children in Manila, the Philippines. Environmental Research, 82, 231-238. http://dx.doi.org/10.1006/enrs.1999.4024

[17] Aguilar-Garduño, C., Lacasaña, M., Tellez-Rojo, M.M., Aguilar-Madrid, G., Sanin-Aguirre, L.H., Romieu, I. and Hernandez-Avila, M. (2003) Indirect Lead Exposure among Children of Radiator Repair Workers. American Journal of Industrial Medicine, 43, 662-667. http://dx.doi.org/10.1002/ajim.10204

[18] Nunez, C.M., Klitzman, S. and Goodman, A. (1993) Lead Exposure among Automobile Radiator Repair Workers and Their Children in New York City. American Journal of Industrial Medicine, 23, 763-777. http://dx.doi.org/10.1002/ajim.4700230510

[19] Ahmad, T., Mumtaz, A., Ahmad, D. and Rashid, N. (2009) Lead Exposure in Children Living around the Automobile and Battery Repair Workshops. Biomedica, 25, 128-132.

[20] Malekirad, A.A., Fani, A., Abdollahi, M., Oryan, S., Babapour, V., Shariatzade, S.M.A. and Davodi, M. (2011) BloodUrine and Cognitive-Mental Parameters in Min Workers Exposed to Lead and Zinc. AMUJ, 13, 106-113.

[21] Shannon, M.W., Borron, S.W and Burns, M.J. (2007) Haddad and Winchester's Clinical Management of Poisoning and Drug Overdose. 4th Edition, Saunders Elsevier, Westline.

[22] Zhang, W., Zhang, G.G., He, H.Z. and Bolt, H.M. (1994) Early Health Effects and Biological Monitoring in Persons Occupationally Exposed to Tetraethyl Lead. International Archives of Occupational and Environmental Health, 65, 395-299. http://dx.doi.org/10.1007/BF00383250

[23] Canfield, R.L., Gendle, M.H. and Cory-Slechta, D.A. (2004) Impaired Neuropsychological Functioning in Lead- Exposed Children. Developmental Neuropsychology, 26, 513-540. http://dx.doi.org/10.1207/s15326942dn2601_8

[24] Nigg, J.T., Knottnerus, G.M., Martel, M.M., Nikolas, M., Cavanagh, K., Karmaus, W. and Rappley, M.D. (2008) Low Blood Lead Levels Associated with Clinically Diagnosed Attention-Deficit/Hyperactivity Disorder and Mediated by Weak Cognitive Control. Biological Psychiatry, 63, 325. http://dx.doi.org/10.1016/j.biopsych.2007.07.013

[25] Maizlish, N.A., Parra, G. and Feo, O. (1995) Neurobehavioural Evaluation of Venezuelan Workers Exposed to Inorganic Lead. Occupational and Environmental Medicine, 52, 408-414. http://dx.doi.org/10.1136/oem.52.6.408

[26] Lindgren, K.N., Masten, V.L., Ford, D.P. and Bleecker, M.L. (1996) Relation of Cumulative Exposure to Inorganic Lead and Neuropsychological Test Performance. Occupational and Environmental Medicine, 53, 472-477. http://dx.doi.org/10.1136/oem.53.7.472

[27] Malekirad, A.A., Oryan, S., Fani, A., Babapor, V., Hashemi, M., Baeeri, M., Bayrami, Z. and Abdollahi, M. (2010) Study on Clinical and Biochemical Toxicity Biomarkers in a Zinc-Lead Mine Workers. Toxicology and Industrial Health, 26, 331-337. http://dx.doi.org/10.1177/0748233710365697

[28] Winneke, G., Krämer, U., Brockhaus, A., Ewers, U., Kujanek, G. and Lechner, H. (1983) Neuropsychological Studies in Children with Elevated Tooth-Lead Concentrations. II. Extended Study. International Archives of Occupational and Environmental Health, 51, 231-252. http://dx.doi.org/10.1007/BF00377755

[29] Lindgren, K.N., Masten, V.L., Ford, D.P. and Bleecker, M.L. (1996) Relation of Cumulative Exposure to Inorganic Lead and Neuropsychological Test Performance. Occupational and Environmental Medicine, 53, 472-477. http://dx.doi.org/10.1136/oem.53.7.472

[30] El-Ansary, A.K., Bacha, A.B. and Ayahdi, L.Y. (2011) Relationship between Chronic Lead Toxicity and Plasma Neurotransmitters in Autistic Patients from Saudi Arabia. Clinical Biochemistry, 44, 1116-1120. http://dx.doi.org/10.1016/j.clinbiochem.2011.06.982

[31] Mehrpour, O., Karrari, P. and Adbollahi, M. (2012) Chronic Lead Poisoning in Iran; a Silent Disease. Daru, $20,8$. http://dx.doi.org/10.1186/2008-2231-20-8

[32] Pourmand, A., Al-Taie, T.K. and Amirshahi, M. (2012) Perspective on Lead Toxicity, a Comparison between the United States and Iran. Daru, 20, 70. http://dx.doi.org/10.1186/2008-2231-20-70 


\section{Abbreviation}

Between blood lead level (BLL)

Mean corpuscular hemoglobin $(\mathrm{MCH})$

White blood cell (WBC)

Mean corpuscular volume (MCV)

Platelet crit (PCT)

Red blood cell (RBC)

Mean corpuscular hemoglobin concentration (MCHC)

Red blood cell distribution width (RDW)

Platelet (PLT)

Mean platelet volume (MPV)

Platelet distribution width (PDW)

Profile of Mood States (POMS)

Wechsler Memory Scale (WMS)

Index body matrix (IBM)

Intelligence quotient (IQ)

Integrated blood levels (IBL)

Gamma amino butyric acid (GABA)

Serotonin (5HT)

Dopamine (DA)

N-methyl-d-aspartate (NMDA) 